\title{
Impact of combined use of intraoperative MRI and awake microsurgical resection on patients with gliomas: a systematic review and meta-analysis
}

\author{
Constantin Tuleasca ${ }^{1,2,3,4}$ (D) Henri-Arthur Leroy ${ }^{1} \cdot$ Iulia Peciu-Florianu ${ }^{1} \cdot$ Ondine Strachowski ${ }^{1} \cdot$ Benoit Derre $^{1}$. \\ Marc Levivier $^{2,3} \cdot$ Michael Schulder $^{5} \cdot$ Nicolas Reyns $^{1}$
}

Received: 5 October 2020 / Revised: 29 December 2020 / Accepted: 25 January 2021 / Published online: 3 February 2021

(C) The Author(s) 2021

\begin{abstract}
Microsurgical resection of primary brain tumors located within or near eloquent areas is challenging. Primary aim is to preserve neurological function, while maximizing the extent of resection (EOR), to optimize long-term neurooncological outcomes and quality of life. Here, we review the combined integration of awake craniotomy and intraoperative MRI (IoMRI) for primary brain tumors, due to their multiple challenges. A systematic review of the literature was performed, in accordance with the Prisma guidelines. Were included 13 series and a total number of 527 patients, who underwent 541 surgeries. We paid particular attention to operative time, rate of intraoperative seizures, rate of initial complete resection at the time of first IoMRI, the final complete gross total resection (GTR, complete radiological resection rates), and the immediate and definitive postoperative neurological complications. The mean duration of surgery was $6.3 \mathrm{~h}$ (median 7.05, range 3.8-7.9). The intraoperative seizure rate was $3.7 \%$ (range 1.4-6; $\mathrm{I}^{\wedge} 2=0 \%$, P heterogeneity $=0.569$, standard error $=0.012, p=0.002$ ). The intraoperative complete resection rate at the time of first IoMRI was $35.2 \%$ (range $25.7-44.7 ; \mathrm{I}^{\wedge} 2=66.73 \%$, P heterogeneity $=0.004$, standard error $=$ $0.048, p<0.001$ ). The rate of patients who underwent supplementary resection after one or several IoMRI was $46 \%$ (range $39.8-$ $52.2 ; \mathrm{I}^{\wedge} 2=8.49 \%$, P heterogeneity $=0.364$, standard error $\left.=0.032, p<0.001\right)$. The GTR rate at discharge was $56.3 \%$ (range $47.5-65.1 ; \mathrm{I}^{\wedge} 2=60.19 \%$, P heterogeneity $=0.01$, standard error $\left.=0.045, p<0.001\right)$. The rate of immediate postoperative complications was $27.4 \%$ (range $15.2-39.6 ; \mathrm{I}^{\wedge} 2=92.62 \%$, P heterogeneity $<0.001$, standard error $=0.062, p<0.001$ ). The rate of permanent postoperative complications was $4.1 \%$ (range $1.3-6.9 ; \mathrm{I}^{\wedge} 2=38.52 \%$, P heterogeneity $=0.123$, standard error $=$ $0.014, p=0.004)$. Combined use of awake craniotomy and IoMRI can help in maximizing brain tumor resection in selected patients. The technical obstacles to doing so are not severe and can be managed by experienced neurosurgery and anesthesiology teams. The benefits of bringing these technologies to bear on patients with brain tumors in or near language areas are obvious. The lack of equipoise on this topic by experienced practitioners will make it difficult to do a prospective, randomized, clinical trial. In the opinion of the authors, such a trial would be unnecessary and would deprive some patients of the benefits of the best available methods for their tumor resections.
\end{abstract}

Keywords Awake $\cdot$ Intraoperative MRI $\cdot$ Primary brain tumors $\cdot$ Resection $\cdot$ Complications

Dr. Tuleasca and Leroy equally contributed as a first author. Dr. Schulder and Reyns equally contributed as a senior author.

Constantin Tuleasca

constantin.tuleasca@chuv.ch; constantin.tuleasca@gmail.com

1 Neurosurgery and Neurooncology Service, Centre Hospitalier Regional Universitaire de Lille, Roger Salengro Hospital, Lille, France

2 Department of Clinical Neurosciences, Neurosurgery Service and Gamma Knife Center, Lausanne University Hospital (CHUV), Lausanne, Switzerland
3 Faculty of Biology and Medicine (FBM), University of Lausanne (Unil), Lausanne, Switzerland

4 Signal Processing Laboratory (LTS 5), Ecole Polytechnique Fédérale de Lausanne (EPFL), Lausanne, Switzerland

5 Department of Neurosurgery, Zucker School of Medicine at Hofstra/ Northwell, Manhasset, NY, USA 


\section{Introduction}

Surgical treatment of primary brain tumors located within or near eloquent areas is challenging. The primary goal is to preserve neurological function, while maximizing the extent of resection to optimize long-term neurooncological outcomes and thus quality of life.

In fact, it has been previously acknowledged that in primary brain tumors, the extent of resection (EOR) is associated with overall survival (OS) [3, 20,44]. Moreover, increase in EOR reduces the incidence of tumor recurrence and further of malignant transformation in low-grade gliomas (LGG) $[1,27]$. However, lesions in eloquent areas pose a particular challenge. Moreover, surgical resection is just a part of the multimodal management of patients with these lesions.

Reports of the use of intraoperative magnetic resonance imaging (IoMRI) have been conflicting with regard to an increase of the EOR $[6,16]$. Intraoperative images were initially considered to lead to a $20 \%$ increase in the volume of total tumor resection [33, 48], especially for low-grade gliomas (LGG). However, in more recent series, this benefit might be considered much higher. The "flip side" benefit is in complication avoidance as a result of images that confirm that surgical goals have been reached. This is of particular importance for "eloquent" brain areas the injury to which can cause neurological deficits that will notably affect quality of life (QoL). The two surgical goals remain maximal EOR, while preserving neurological function [43].

The use of intraoperative electrical stimulation has become an accepted standard for defining cortical areas underlying eloquent function $[2,8,34]$. Use of this method has been shown to improve functional outcomes for surgical resection in close proximity to eloquent areas of cortical function [55].

Awake craniotomy has a long neurosurgical track record and is usually recommended for patients who need removal of lesions from the areas of eloquent brain where language function would be at risk, and in surgery for medically refractory epilepsy. The current goal of such surgery is to preserve neurological functions including motor, language, and cognitive, for patients with any type of lesions observed near or within eloquent areas of the brain [30].

Here, we sought to review the combined use and integration of the operative techniques of awake craniotomy and IoMRI [23]. Both pose multiple challenges and concerns with regard to multiple aspects, including patient selection, airway control during surgery, operative setup, physical constraints, prolonged operative time, costs, patient comfort, and safety issues.

\section{Methodology}

A PubMed search was performed for entries between January 1990 and February 2020 using the following query guidelines: ((awake AND (intraoperative OR intraoperative MRI, IoMRI)) AND (glioma)). We selected 1990 as a starting date to be sure we did not miss any relevant reference. Inclusion criteria required that each article be a peer-reviewed clinical study or case series of primary brain tumors treated with microsurgical resection, using both the IoMRI and the awake setting. As such, case reports, non-English studies, and conference papers or abstracts were not included. Exclusion criteria included studies reporting nontumoral cases. The article selection is illustrated in Fig. 1, which included the studies reported further in Tables 1, 2, 3, and 4. Two separate reviewers applied the inclusion criteria to the PubMed search result; there were no disagreements. Moreover, four separate reviewers applied the exclusion criteria to the remaining articles. Were included 13 series and a total number of 527 patients, who underwent 541 surgeries.

This study was performed in accordance with the published Preferred Reporting Items for Systematic Reviews and MetaAnalyses (PRISMA) guidelines [29].

We paid particular attention to operative time, rate of intraoperative seizures, rate of initial complete resection at the time of first IoMRI, the final complete resection rates at the time of last IoMRI, and the immediate and definitive postoperative neurological complications.

\section{Statistical analysis using OpenMeta (Analyst) and random-effects model}

Due to the high variation in study characteristics, a statistical analysis using a binary random-effects model (DerSimonian-Laird method) was performed. We used OpenMeta (Analyst) from the Agency for Healthcare Research and Quality.

Weighted summary rates were determined using metaanalytical models. Testing for heterogeneity was performed for each meta-analysis.

Pooled estimates using meta-analytical techniques were obtained for all the outcomes previously described in the same section.

Case reports [36] or series not reporting the outcomes for all included patients were excluded [38].

\section{Results}

\section{Number of studies and number of patients}

Were included 13 series, encompassing a total number of 527 patients, who underwent 541 surgeries. All studies were retrospective cohort analysis.

The number of included patients ranged from 10 to 106 . Most commonly used MRI fields were 1.5 and 3 Tesla. 
Fig. 1 PRISMA flowchart
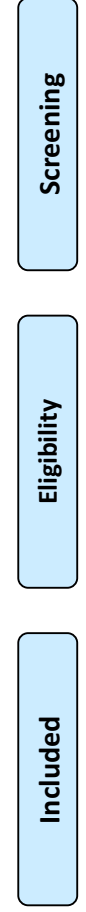

\section{Duration of surgery}

The exact duration of surgery can be found in Table 1 and in Fig. 2. The mean duration of surgery was 6.3 hours (median 7.05, range 3.8-7.9). This has been reported on 6 studies, including 144 patients[22, 26, 30, 54, 56, 58].

\section{Intraoperative seizure rate}

The intraoperative seizure rate was $3.7 \%$ (range $1.4-6$; $\mathrm{I}^{\wedge} 2=$ $0 \%$, P heterogeneity $=0.569$, standard error $=0.012, p=$ 0.002). This has been reported in 4 studies, including 242 patients [12, 26, 31, 59]

\section{Complete resection at the time of first loMRI}

The intraoperative GTR rate at the time of first IoMRI was $35.2 \%$ (range $25.7-44.7 ; \mathrm{I}^{\wedge} 2=66.73 \%, \mathrm{P}$ heterogeneity $=$ 0.004 , standard error $=0.048, p<0.001)$. This has been reported in 10 studies, including 303 patients (Fig. 3) [5, 12, 24, 26, $31,54,56,59,61]$.

\section{Patients who underwent complementary resection after IoMRI}

The rate of patients who underwent supplementary resection after one or several IoMRI was 46\% (range 39.8-52.2; $\mathrm{I}^{\wedge} 2=$ $8.49 \%$, P heterogeneity $=0.364$, standard error $=0.032, p<$ $0.001)$. This has been reported in 8 studies, including 255 patients [12, 22, 24, 26, 30, 56, 58, 59].

Moreover, the increment of complete resection after IoMRI was clearly reported in few studies [24, 26, 61].

\section{Gross total resection rates at discharge}

The complete resection rate at discharge was $56.3 \%$ (range 47.5-65.1; $\mathrm{I}^{\wedge} 2=60.19 \%$, P heterogeneity $=0.01$, standard error $=0.045, p<0.001)$.

\section{Immediate neurological complications}

The rate of immediate postoperative complications was $27.4 \%$ (range 15.2-39.6; $\mathrm{I}^{\wedge} 2=92.62 \%, \mathrm{P}$ heterogeneity $<0.001$, standard error $=0.062, p<0.001)$. This has been reported in 
Table 1 Basic demographic data

\begin{tabular}{|c|c|c|c|c|c|c|c|}
\hline Series* & $\begin{array}{l}N \text { pts, } \\
\text { surgeries }\end{array}$ & $\begin{array}{l}\text { Age (years) } \\
\text { mean (range) }\end{array}$ & $\begin{array}{l}\text { MRI } \\
\text { (Tesla) }\end{array}$ & $\begin{array}{l}\text { Left (L):right }(\mathrm{R}) \\
\text { hemisphere }\end{array}$ & $\begin{array}{l}\text { Average operative } \\
\text { time }(\mathrm{h})\end{array}$ & $\begin{array}{l}\text { Average IoMRI } \\
\text { time (min) }\end{array}$ & $\begin{array}{l}\text { Intraoperative } \\
\text { seizures }\end{array}$ \\
\hline Nabavi et al. (2008) & 34,38 & & 1.5 & $32: 6$ & - & - & $3 / 38(7.9 \%)$ \\
\hline Weingarten et al. (2009) & 10,10 & $25-57$ & 1.5 & - & $6.8 \mathrm{~h}(3.8-8.7)$ & - & \\
\hline Leuthardt et al. (2011) & 12 & $32-60$ & 1.5 & $9: 3$ & $7.9(5.9-9.7)$ & $45(28.8-69)$ & \\
\hline Lu et al. (2012) & 30 & $45.5(19-67)$ & 3 & - & - & - & \\
\hline Tuominen et al. (2013) & 20 & $44(16-67)$ & 0.23 & - & $4.45(3.20-7.55)$ & - & \\
\hline Maldaun et al. (2014) & 41,42 & $41.2(22-70)$ & 1.5 & $31: 11$ & $7.3(4-13.9)$ & $15.6(5.1-27.1)$ & $3 / 42(7 \%)$ \\
\hline Coburger et al. (2015) & 26 & - & - & - & - & - & - \\
\hline Ghinda et al. (2016) & 106 & $41.7(18-76)$ & 3 & & & & $\begin{array}{l}3 / 106(2 \%) \\
1 / 106(0.9 \%, \\
\text { generalized } \\
\text { seizure })\end{array}$ \\
\hline Zhuang et al. (2016) & 20 & $45(27-67)$ & 3 & & & & \\
\hline Mehdorn et al. (2017) & 106 & - & - & - & - & - & - \\
\hline Motomura et al. (2017) & 25,33 & $41(28-67)$ & 0.4 & $30: 3$ & $7.8(4.4-12)$ & & \\
\hline White et al. (2018) & 36 & & 0.15 & & $3.8(2-6)$ & 15 & \\
\hline Whiting et al. (2020) & 61,62 & $44.5(19-78)$ & & $44: 17$ & & & $2 / 63(3.2 \%)$ \\
\hline
\end{tabular}

*13 series including a total of 527 patients, who underwent 541 surgeries, $h$ hours, IoMRI intraoperative MRI

11 studies, including 410 patients (Fig. 4) [12, 22, 24, 26, 30, $31,54,56,58,59,61]$.

\section{Permanent neurological complications}

The rate of permanent postoperative complications was $4.1 \%$ (range $1.3-6.9 ; \mathrm{I}^{\wedge} 2=38.52 \%$, P heterogeneity $=0.123$, standard error $=0.014, p=0.004)$. This has been reported in 8 studies, including 324 patients [12, 22, 24, 26, 30, 54, 59, 61]

\section{Discussion}

\section{Overall outcomes}

In the present meta-analysis, we review the published literature on the use of awake microsurgical resection combined with intraoperative MRI. The mean intraoperative seizure rate was $3.7 \%$. The mean initial (at the time of first IoMRI) and final (at the time of discharge) GT resection rates were $35.2 \%$ and $56.3 \%$, respectively, including $46 \%$ of patients who had additional resection performed after intraoperative images showed residual tumor that could be safely resected.

The mean rate of immediate and permanent postoperative complications was $27.4 \%$ and $4.1 \%$, respectively. Several aspects warrant for further interest and are detailed below.

\section{Intraoperative MRI for glioma surgery and its benefits in general}

It has been previously acknowledged that IoMRI increases the extent of resection and thus the overall survival in high-grade gliomas [49]. Moreover, for patients with low-grade gliomas, the use of IoMRI showed higher resection rates [15]. In this context, a recent and large multicentric trial showed that GT resection was an independent positive prognostic factor for PFS in lowgrade gliomas and confirmed that IoMRI was significantly associated with GT resection [5]. In sum, intraoperative MRI data can be used to localize tumor remnants reliably and can also compensate for the effects of brain shift [32].

\section{Intraoperative MRI and mapping}

Currently, the cornerstone of treatment for low- and high-grade gliomas is maximal safe resection. Structural information related to tumor architecture as depicted by MRI studies should be completed, whenever necessary, with mapping modalities, determining the relationship of the tumor itself with the eloquent cortex and subcortical areas to avoid. The success of microsurgical resection for brain lesions close to eloquent cortex is linked to preservation and/or improvement of neurological functions and, thus, of the quality of life [11]. Integrating anatomical and functional data into the neuronavigation has nowadays become a standard of care in many departments dealing with neurooncology [25]. Moreover, advancement in neuroimaging and neurophysiological techniques and the appearance of the IoMRI have created a major paradigm shift and increased the EOR.

The main utility of the IoMRI is related to the compensation of brain shift and in intraoperative control of the 
Table 2 Function mapped, anatomical location, exact histology

\begin{tabular}{|c|c|c|c|}
\hline Series & Function mapped & Anatomical location & Exact histology \\
\hline Nabavi et al. (2008) & - & $\begin{array}{l}\text { - L frontal operculum } \\
\text { - L SMA } \\
\text { - Dorsal temporal lobe }\end{array}$ & - \\
\hline Weingarten et al. (2009) & $\begin{array}{l}\text { - Language }(n=5) \\
\text { - Motor }(n=7) \\
\text { - Sensory }(n=6)\end{array}$ & $\begin{array}{l}\text { - L temporal lobe }(n=4) \\
\text { - Posterior L frontal }(n=1) \\
\text { - Posterior R frontal }(n=1) \\
\text { - L parietal }(n=1) \\
\text { - R parietal }(n=1)\end{array}$ & - \\
\hline Leuthardt et al. (2011) & $\begin{array}{l}- \text { Language }(n=3) \\
\text { - Motor }(n=1) \\
\text { - Both }(n=8)\end{array}$ & $\begin{array}{l}\text { - L frontal }(n=14) \\
\text { - insula }(n=8) \\
\text { - Parietal }(n=4) \\
\text { - Temporal }(n=4)\end{array}$ & $\begin{array}{l}\text { - Oligoastrocytoma } 3 / 12 \\
\text { - Oligodendroglioma } 2 / 12 \\
\text { - Anaplastic astrocytoma } 1 / 12 \\
\text { - Anaplastic oligoastrocytoma } 3 / 12 \\
\text { - Anaplastic oligodendroglioma } 1 / 12 \\
\text { - Glioblastoma } 3 / 12\end{array}$ \\
\hline Lu et al. (2012) & - & $\begin{array}{l}\text { - Frontal }(n=14) \\
\text { - Insular }(n=8) \\
\text { - Parietal }(n=4) \\
\text { - Temporal }(n=4)\end{array}$ & $\begin{array}{l}\text { - Oligoastrocytoma } 2 / 30 \\
\text { - Oligodendroglioma } 4 / 30 \\
\text { - Diffuse astrocytoma } 13 / 30 \\
\text { - Anaplastic oligodendroglioma } 1 / 30 \\
\text { - Glioblastoma } 10 / 30\end{array}$ \\
\hline Tuominen et al. (2013) & - & $\begin{array}{l}\text { - Frontal }(n=6) \\
\text { - Parietal }(n=3) \\
\text { - Temporal }(n=4) \\
\text { - More than one lobe }(n=7)\end{array}$ & $\begin{array}{l}\text { - DNET } 1 / 20 \\
\text { - Oligodendroglioma II (4/20), III (3/20) } \\
\text { - Astrocytoma II }(2 / 20), \text { III }(3 / 20) \\
\text { - Glioblastoma }(4 / 20)\end{array}$ \\
\hline Maldaun et al. (2014) & $\begin{array}{l}\text { - Language }(n=9) \\
\text { - Speech and motor }(n=21) \\
\text { - Motor }(n=12)\end{array}$ & $\begin{array}{l}\text { - Frontal }(n=17) \\
\text { - Parietal }(n=4) \\
\text { - Temporal }(n=5) \\
\text { - More than one lobe }(n=9) \\
\text { - Insular }(n=7)\end{array}$ & $\begin{array}{l}\cdot \text { II and III }(n=14) \\
\cdot \text { IV }(n=28)\end{array}$ \\
\hline Coburger et al. (2015) & - Language $(n=26)$ & - & - \\
\hline Ghinda et al. (2016) & - & $\begin{array}{l}\text { - Frontal }(n=48) \\
\text { - Parietal }(n=9) \\
\text { - Temporal }(n=18) \\
\text { - Insular }(n=31)\end{array}$ & $\begin{array}{l}\text { - Oligoastrocytoma } 2 / 30 \\
\text { - Oligodendroglioma } 4 / 30 \\
\text { - Diffuse astrocytoma } 13 / 30 \\
\text { - Anaplastic oligodendroglioma 1/30 } \\
\text { - Glioblastoma 10/30 }\end{array}$ \\
\hline Mehdorn et al. (2017) & - & - & $\begin{array}{l}\text { - Astrocytoma II 10/106 } \\
\text { - Astrocytoma III 22/106 } \\
\text { - Oligoastrocytoma 3/106 } \\
\text { - Oligodendroglioma II 4/106 } \\
\text { - Oligoastrocytoma III 5/106 } \\
\text { - Anaplastic oligodendroglioma 6/106 } \\
\text { - Glioblastoma 46/106 } \\
\text { - Recurrent glioblastoma 6/106 } \\
\text { - Gliosarcoma 2/106 }\end{array}$ \\
\hline Motomura et al. (2017) & - & $\begin{array}{l}\text { - Frontal }(n=15) \\
\text { - Parietal }(n=5) \\
\text { - Temporal }(n=1) \\
\text { - Insular }(n=11) \\
\text { - Occipital }(n=1)\end{array}$ & $\begin{array}{l}\text { - Astrocytoma II 9/33 } \\
\text { - Oligodendroglioma II 2/33 } \\
\text { - Oligoastrocytoma } 7 / 33 \\
\text { - Anaplastic astrocytoma III 2/33 } \\
\text { - Anaplastic oligodendroglioma 5/33 } \\
\text { - Glioblastoma 4/33 } \\
\text { - Pleomorphic xantoastrocytoma } 1 / 33 \\
\text { - Gliosis } 3 / 33\end{array}$ \\
\hline White et al. (2018) & - Purely language (22/36) & - & $\begin{array}{l}\text { - Glioblastoma } 17 / 36 \\
\text { - Astrocytoma } 8 / 36 \\
\text { - Oligodendroglioma } 7 / 36 \\
\text { - Ganglioglioma } 1 / 36 \\
\text { - Mesial temporal sclerosis }(1 / 36) \\
\text { - Cysticercosis }(2 / 36)\end{array}$ \\
\hline Whiting et al. (2020) & $\begin{array}{l}\text { - Speech alone } 23 / 62(37.1 \%) \\
\text { - Motor alone } 24 / 62(38.7 \%) \\
\text { - Both speech and motor } 15 / 62(24.2 \%)\end{array}$ & $\begin{array}{l}\text { - Frontal }(n=34) \\
\text { - Temporal }(n=7) \\
\text { - Parietal }(n=9) \\
\text { - Frontal, extending adjacent lobes }(n=6) \\
\text { - Temporal, extending to adjacent lobes }(n=4) \\
\text { - Insular }(n=1)\end{array}$ & $\begin{array}{l}\cdot \text { II }(28 / 63) \\
\cdot \text { III }(15 / 63) \\
\cdot \text { IV }(18 / 63)\end{array}$ \\
\hline
\end{tabular}


Table 3 Pertinent data with regard to tumor resection

\begin{tabular}{|c|c|c|c|c|c|c|}
\hline Series & $\begin{array}{l}\text { Volumes } \\
\text { Mean } \\
\text { (range) }\end{array}$ & $\begin{array}{l}\text { IoMRI complete } \\
\text { resection }\end{array}$ & $\begin{array}{l}\text { No further } \\
\text { resection } \\
(n, \text { percentage) }\end{array}$ & $\begin{array}{l}\text { Further } \\
\text { resection }\end{array}$ & Complete resection (details) & $\begin{array}{l}\text { EOR (before and } \\
\text { after IoMRI) } \\
\text { Mean, range }\end{array}$ \\
\hline Nabavi et al. (2008) & - & - & - & - & Yes & - \\
\hline $\begin{array}{l}\text { Weingarten et al. } \\
\text { (2009) }\end{array}$ & - & $1 / 10(10 \%)$ & $2 / 9(22.2 \%)$ & $7 / 9(77.8 \%)$ & $\begin{array}{l}7 / 10(70 \%) \text { complete } \\
3 / 10(30 \%) \text { to an eloquent } \\
\text { margin }\end{array}$ & \\
\hline Leuthardt et al. (2011) & - & $7 / 12(58.3 \%)$ & $5 / 12(41.7 \%)$ & $6 / 12(50 \%)$ & $\begin{array}{l}5 / 12(41.7 \%) \text { complete } \\
2 / 12(16.7 \%) \text { nearly total } \\
5 / 12(41.7 \%) \text { subtotal }\end{array}$ & - \\
\hline Lu et al. (2012) & $\begin{array}{l}60 \\
(8.4-216.7)\end{array}$ & $11 / 30(36.7 \%)$ & $19 / 30(63.3 \%)$ & $11 / 30(36.7 \%)$ & $\begin{array}{l}18 / 30(60 \%) \text { complete } \\
\text { (grace to IoMRI } 7 / 18(60 \%) \text { ) }\end{array}$ & $\begin{array}{l}92.5 \%(75.1-97) \\
100 \%(92.6-100)\end{array}$ \\
\hline Tuominen et al. (2013) & - & - & - & & $10 / 20(50 \%)$ complete & - \\
\hline Maldaun et al. (2014) & $\begin{array}{l}49 \\
(3.3 .-154.2)\end{array}$ & - & $25 / 42(59.5 \%)$ & $17 / 42(40.5 \%)$ & $\begin{array}{l}17 / 42 \text { gross total }(40.5 \%) \\
\text { (grace to IoMRI } 7 / 17(41 \%) \text { ) }\end{array}$ & $\begin{array}{l}56 \% \\
67 \%\end{array}$ \\
\hline Coburger et al. (2015) & - & - & - & & $17 / 26(65.4 \%)$ & - \\
\hline Ghinda et al. (2016) & $\begin{array}{l}58 \\
(3.5-181.3)\end{array}$ & $44 / 106(41.5 \%)$ & $32 / 62(51.6 \%)$ & $30 / 62(48.4 \%)$ & $64 / 106(60.4 \%)$ & - \\
\hline Zhuang et al. (2016) & - & $\begin{array}{l}16 / 30(53 \%) \\
\text { GTR }\end{array}$ & - & - & $23 / 30(77 \%)$ & $\begin{array}{l}53 \% \\
77 \%\end{array}$ \\
\hline Mehdorn et al. (2017) & - & - & - & - & - & - \\
\hline Motomura et al. (2017) & $\begin{array}{l}46.1 \\
(0.6-196.4)\end{array}$ & $9 / 25(36 \%)$ & $9 / 16(56.2 \%)$ & $7 / 16(43.8 \%)$ & - & - \\
\hline White et al. (2018) & - & $12 / 36(33 \%)$ & $16 / 24(66.7 \%)$ & $18 / 36(50 \%)$ & - & - \\
\hline Whiting et al. (2020) & - & $14 / 62(22.6 \%)$ & $7 / 48(14.6 \%)$ & $41 / 48(85.4 \%)$ & $27 / 63(42.8 \%)$ & - \\
\hline
\end{tabular}

microsurgical resection. Other imaging modalities can be further added, including functional MRI or diffusion tensor imaging, with the illustration of relevant tracts. The former is, however, limited by the radiological aspect of the intraoperative field, state of resection, etc. Combining IOM and IoMRI provides functional and structural information, which is extremely useful for the neurosurgeon, enabling higher resection rates, while preserving quality of life.

\section{Awake surgery contraindications}

Awake surgery cannot be done in patients with pronounced aphasia, those who have minimal enough residual motor function, a score under 23 on the Mini Mental Status Examination, and those with apathic/disorganized behavior [31]. Other authors included also large body mass index and potentially difficult airway as reasons to rule out awake surgery [22].
Table 4 Postoperative neurological outcomes

\begin{tabular}{llll}
\hline Series & $\begin{array}{l}\text { Immediate neurological } \\
\text { complications }\end{array}$ & $\begin{array}{l}\text { Persisting neurological } \\
\text { complications }\end{array}$ & $\begin{array}{l}\text { Neurological stability/ } \\
\text { improvement }\end{array}$ \\
\hline Nabavi et al. (2008) & $0 / 38(0 \%)$ & - & - \\
Weingarten et al. (2009) & $3 / 10(30 \%)$ & - & - \\
Leuthardt et al. (2011) & $5 / 12(41.7 \%)$ & $1 / 12(8.3 \%)$ & $11 / 12(91.7 \%)$ \\
Lu et al. (2012) & $12 / 30(40 \%)$ & $1 / 30(3.3 \%)$ & - \\
Tuominen et al. (2013) & $2 / 20(10 \%)$ & $1 / 20(5 \%)$ & $16 / 20(80 \%)$ \\
Maldaun et al. (2014) & $11 / 42(26.2 \%)$ & $1 / 42(2.3 \%)$ & - \\
Coburger et al. (2015) & - & - & - \\
Ghinda et al. (2016) & $48 / 106(46.2 \%)$ & $9 / 106(8.7 \%)$ & - \\
Zhuang et al. (2016) & $10 / 20(50 \%)$ & $1 / 18(5.6 \%)$ & - \\
Mehdorn et al. (2017) & - & - & - \\
Motomura et al. (2017) & $17 / 33(51.5 \%)$ & $4 / 33(12 \%)$ & - \\
White et al. (2018) & $3 / 36(8.3 \%)$ & - & - \\
Whiting et al. (2020) & $8 / 63(12.7 \%)$ & $0 / 63(0 \%)$ & \\
\hline
\end{tabular}


Fig. 2 The mean, minimal, and maximal operative times (in hours)

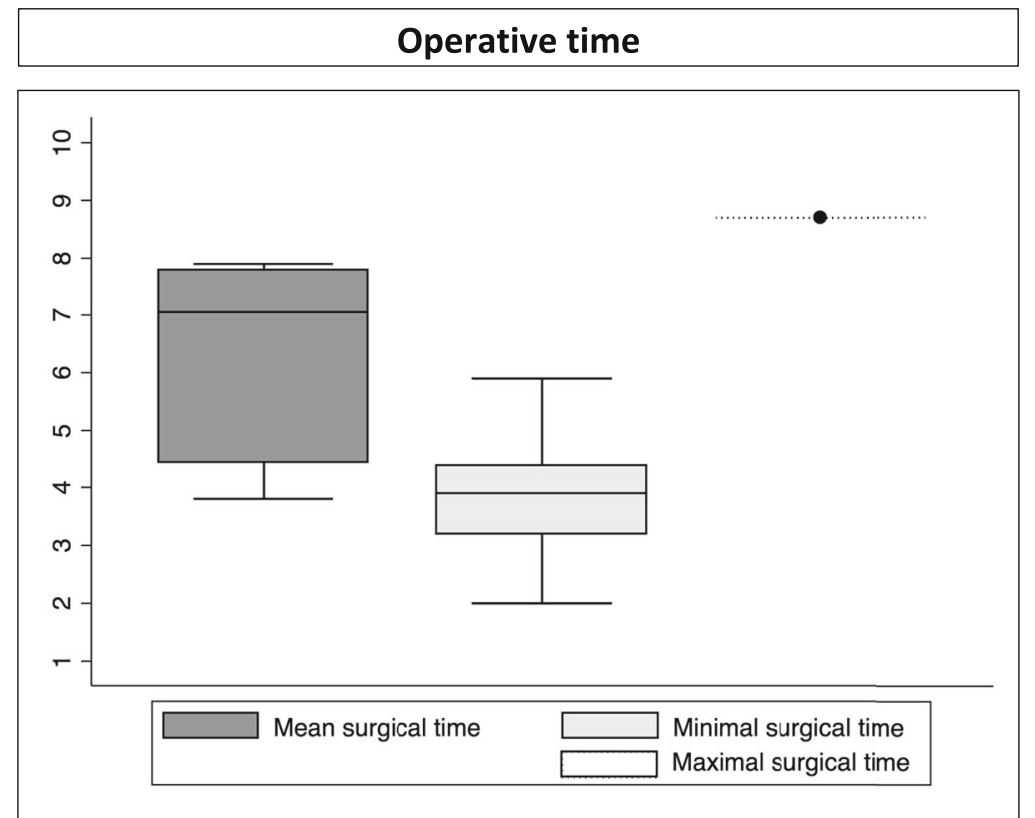

\section{The major role of the anesthesiology team}

The role of the anesthesiologist is crucial both preoperatively, to determine if the patient is a suitable candidate (both at medical and emotional levels, in terms of complete comfort during the procedure), and intraoperatively (patient able to talk and to follow commands [4]).

\section{Patient position}

The patient should be positioned in a way that she/he could have a large visual field view, including of the neuropsychologist's team. Moreover, the patient should be able to visualize any images or numbers seen on the computer and further needing to be described.

The patient installation could also benefit from a transparent sterile field towards the neuropsychologists and anesthesiologists side, so as to facilitate the contact with both teams.

\section{The most common, the "AAA" technique}

The most common procedure is a combination of general anesthesia and an awake technique, in what is known as the "asleep awake asleep" (AAA) technique. By this approach, the patient is placed under general anesthesia (without intubation) before and after brain tumor resection in awake. Usually, there is an initial phase of general anesthesia, followed by intraoperative awakening, and finally back to general anesthesia for the end of the surgery [40]. However, not all studies specifically detailed their awake technique. An important adjunct can be, in selected cases, intraoperative hypnosis [60].

\section{Intraoperative focal seizures}

Cortical stimulation can provoke a seizure, the incidence of which is estimated to be between 5 and 20\% [47]. These episodes usually can be managed by cold Ringer's lactate solution irrigation of the cortex and patience, without the need for intravenous antiepileptic medication [46]. Postictal paresis might further limit the progress of surgery. Moreover, repeated seizures might lead to a long postictal period that can render the continuation of surgery difficult if not impossible. Of note, potential brain swelling can further complicate continuing the surgery. Hence, the interest of starting to progressively stimulate from lower to higher intensity.

\section{Cortical mapping}

Penfield and Boldrey [37] first mapped the motor and sensory homunculi by stimulating the cerebral cortex with a monopolar electrode in conscious patients undergoing brain surgery for epilepsy. Bipolar ESM was later used during tumor surgery and for language area localization [57]. More recently, ESM has further been used to identify critical subcortical white matter tracts [10]. Motor mapping can be performed in patients under general anesthesia, with various results [42]. Of note, stronger cortical stimulation can favor ictal events; hence, the interest to couple it with EMG. However, speech mapping must be performed awake. Motor and speech testing are rehearsed before surgery. The most complex remains speech monitoring, ranging from naming to association and free narration. For speech localization during awake surgery, object naming is preferred to number counting. The 


\section{Microsurgical complete resection rates}

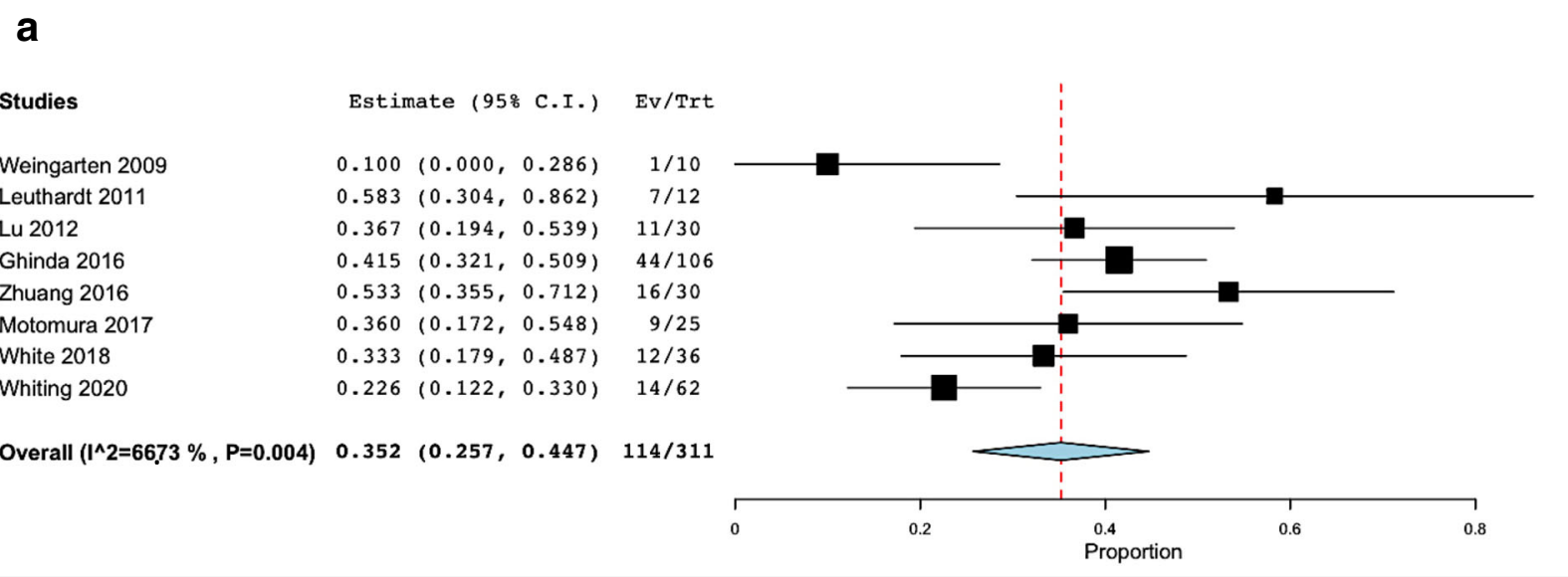

\section{b}

Studies

Weingarten 2009

Leuthardt 2011

Lu 2012

Maldaun 2014

Ghinda 2016

Motomura 2017

White 2018

Whiting 2020

Estimate (958 C.I.) Ev/Trt

$0.778(0.506,1.000) \quad 7 / 9$

$0.500(0.217,0.783) \quad 6 / 12$

$0.367(0.194,0.539) \quad 11 / 30$

$0.405(0.256,0.553) \quad 17 / 42$

$0.484(0.359,0.608) \quad 30 / 62$

$0.438(0.194,0.681) \quad 7 / 16$

$0.500(0.337,0.663) \quad 18 / 36$

$0.429(0.306,0.551) \quad 27 / 63$

Overall $\left(I^{\wedge} 2=8.50 \%, P=0.364\right) \quad 0.460(0.398,0.522) \quad 123 / 270$

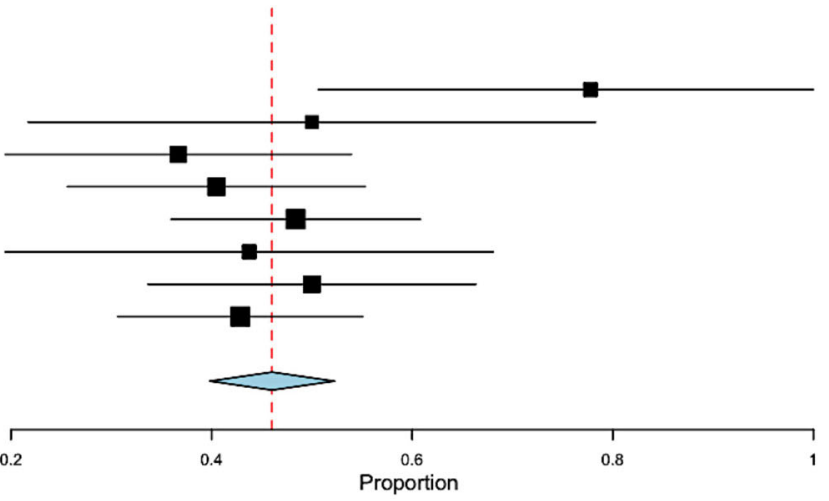

C

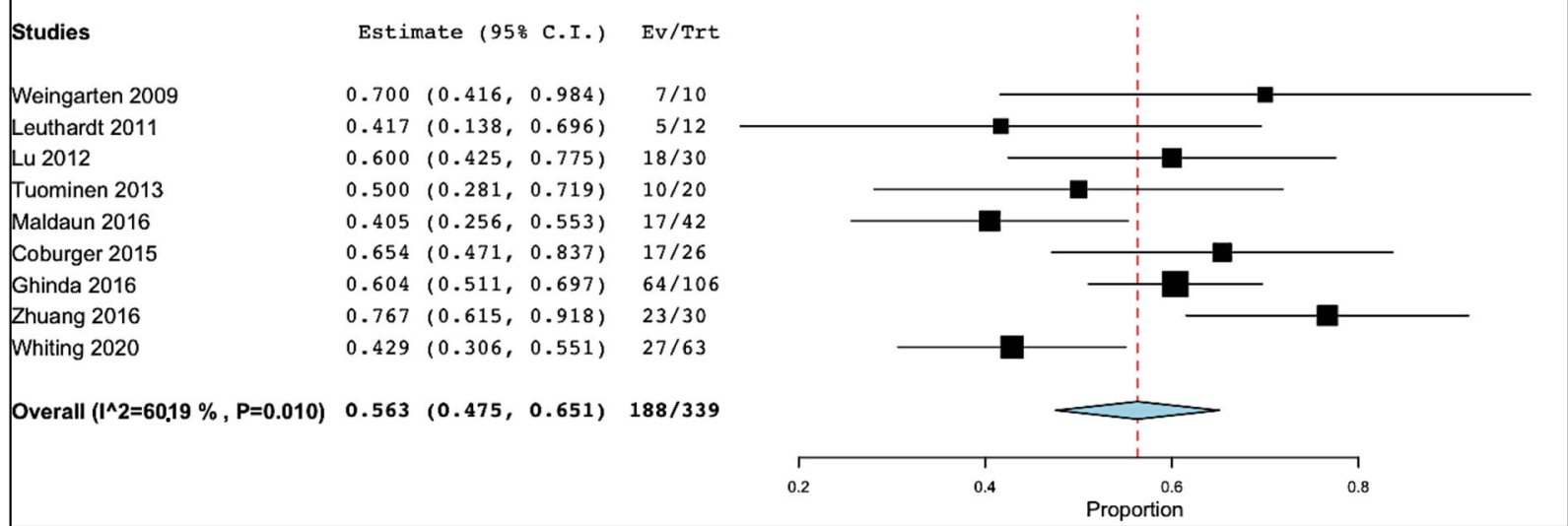

Fig. 3 (A) Complete resection rates at the time of first IoMRI. (B) Patients benefitting from additional resection. (C) Final complete resection rates

heterogeneity of cortical areas activated during speech formation makes the cortical mapping of these areas in practice more demanding and time consuming compared to mapping motor areas [39]. 


\section{Neurological complications}

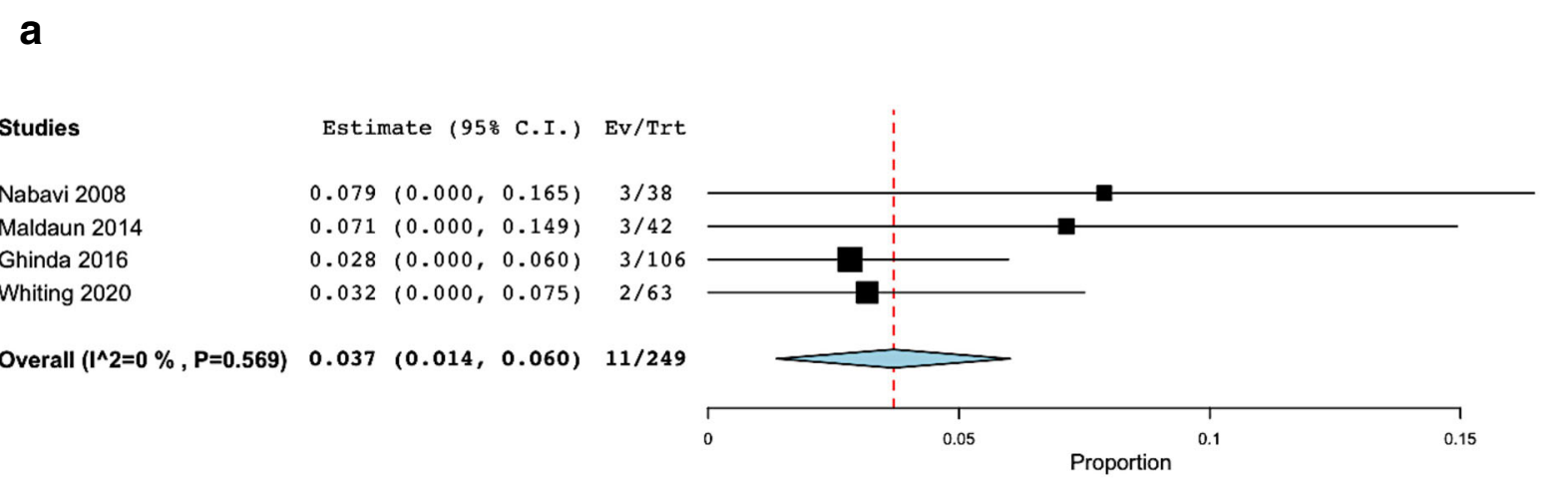

\section{b}

Studies

Nabavi 2008

Weingarten 2009

Leuthardt 2011

Lu 2012

Tuominen 2013

Maldaun 2014

Ghinda 2016

Zhuang 2016

Motomura 2017

White 2018

Whiting 2020

Overall $\left(I^{\wedge} 2=9262 \%, P<0.001\right)$
Estimate ( $95 \%$ C.I.) Ev/Trt

$0.013(0.000,0.048) \quad 0 / 38$

$0.300(0.016,0.584) \quad 3 / 10$

$0.417(0.138,0.696) \quad 5 / 12$

$0.400(0.225,0.575) \quad 12 / 30$

$0.100(0.000,0.231) \quad 2 / 20$

$0.262(0.129,0.395) \quad 11 / 42$

$0.453(0.358,0.548) \quad 48 / 106$

$0.500(0.281,0.719) \quad 10 / 20$

$0.515(0.345,0.686) \quad 17 / 33$

$0.083(0.000,0.174) \quad 3 / 36$

$0.127(0.045,0.209) \quad 8 / 63$

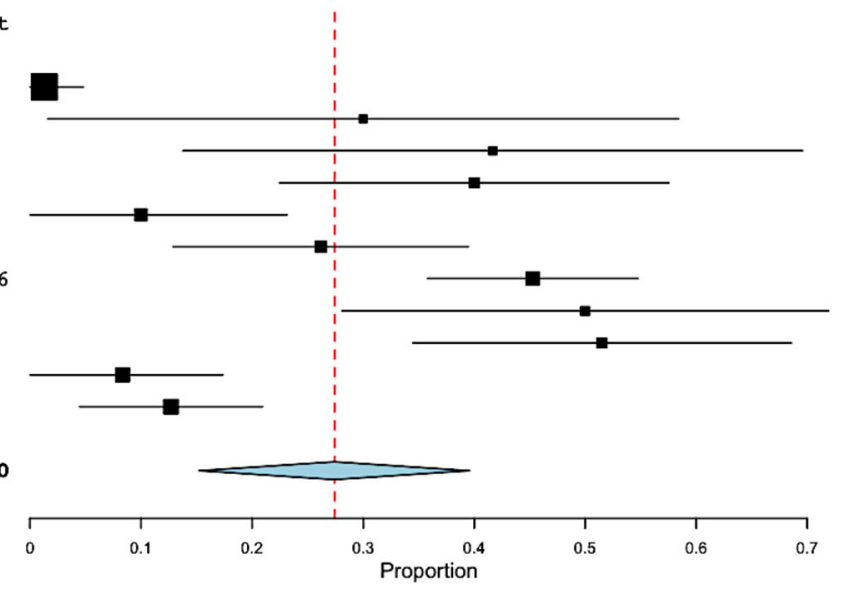

C

Studies

Leuthardt 2011

Lu 2012

Tuominen 2013

Maldaun 2014

Ghinda 2016

Zhuang 2016

Motomura 2017

Whiting 2020

Overall (I^2=38.52\%, P=0.123) $0.041 \quad(0.013,0.069) \quad 18 / 324$

Estimate (95\% C.I.) Ev/Trt

$0.083(0.000,0.240) 1 / 12$

$0.033(0.000,0.098) 1 / 30$

$0.050(0.000,0.146) \quad 1 / 20$

$0.024(0.000,0.070) \quad 1 / 42$

$0.085(0.032,0.138) \quad 9 / 106$

$0.056(0.000,0.161) \quad 1 / 18$

$0.121(0.010,0.233) 4 / 33$

$0.008(0.000,0.029) 0 / 63$
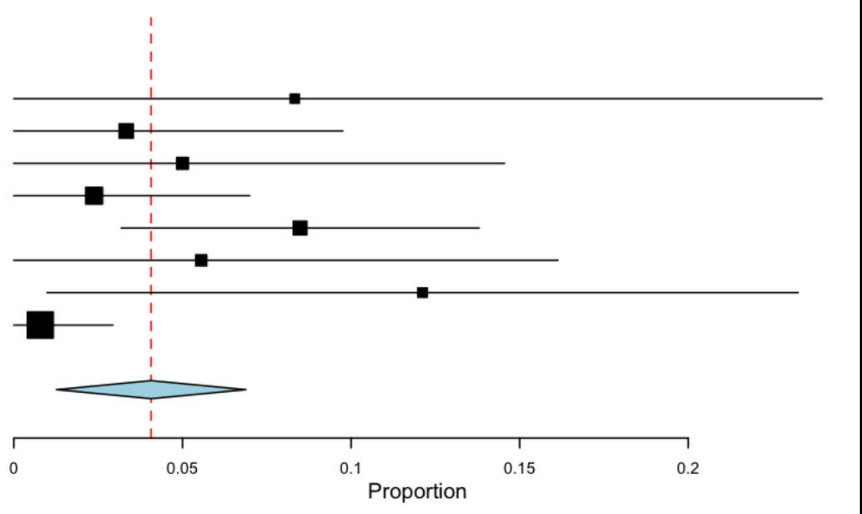

Fig. 4 Neurological complications. (A) Intraoperative partial seizures. (B) Immediate postoperative complications. (C) Permanent postoperative complications 
Cortical mapping is thus a method that delinates functional areas during brain tumor surgery and preventing inadvertent injury to eloquent cortical and subcortical structures [57]. Many groups use the Ojemann bipolar cortical stimulator (Integra Inc). This probe has a $5-\mathrm{mm}$ spacing between the electrodes. It relies on a constant current generator that produces a train of square-wave biphasic pulses. The most common settings include a $1 \mathrm{msec}$ phase duration at a frequency of $60 \mathrm{~Hz}$. For localization of primary language and motor cortices, stimulus is applied in increments starting at $1 \mathrm{~mA}$. The Rolandic cortex may also be identified by somatosensory evoked potentials, to identify phase reversal and latency shift. No cortical site is stimulated twice in succession. Usually $2-3 \mathrm{~mA}$ is the maximum stimulus needed to localize the language center in an awake patient. In an asleep case, $10 \mathrm{~mA}$ may be needed to localize the motor cortex. If used correctly, a metaanalysis showed less than $4 \%$ rate of permanent severe neurological deficits in patients after resection with intraoperative stimulation mapping [7]. Of note, monopolar probe can be also safely used in an IoMRI setting both for navigation and stimulation purposes during the resection of primary brain tumors under general anesthesia [41]. Additionally, subcortical MEP mapping can be of further help to evaluate the distance towards the corticospinal tract during resection of motor-eloquent lesions thus reducing the risk of neurological deficit [50]. Combining information about intraoperative corticospinal tract together with direct electrical stimulation in the setting of IoMRI can enhance resection of brain tumors, with up to $77 \%$ having a GTR, as suggested by some authors [18].

\section{Language tasks of specific interest}

Three language tasks should be performed: counting from 1 to a specific number (e.g., 50), picture naming, and word reading. One should also distinguish language deficits (speech arrest, anomia, or alexia) from dysarthria, which is caused by involuntary muscle (mouth or pharyngeal) contraction.

To localize language areas, fMRI and brain mapping using DCS have been commonly applied. Although fMRI is a noninvasive test, it has limited spatial resolution, with various sensitivity and specificity $[13,51]$. The fMRI language activations do not necessarily correlate with intraoperative cortical stimulation findings. Moreover, because of the complexity of language area representation, fMRI has limited ability compared with cortical mapping for identification of such area; in fact, fMRI can be used for identifying language lateralization (left or right hemisphere), but less for precisely pointing out the cortical areas involved in language [53]. Therefore, DCS has been shown to be a reliable predictor of functional recovery $[9,45]$

\section{Cortical resection}

Cortical resection has to be performed at least $1-2 \mathrm{~cm}$ from areas of motor, sensory, or essential language function as identified by ESM [56]. However, more conservative recommendations suggest resection margins within 1-2 cm for speech function, and up to $0.5 \mathrm{~cm}$ for sensory and motor cortices. However, such conservative recommendation might preclude a maximal EOR. The neuropsychologist monitors the motor and speech function throughout the procedure. The authors increased the frequency of checks when the surgeons approached an identified area of eloquence. A resection, which is stopped if speech function deteriorates, can be resumed if clinical resolution resumes within $5 \mathrm{~min}$.

\section{Extent of resection}

In some of the series, there was no statistically significant difference in terms of EOR between low-grade and highgrade gliomas [26], while in others GTR was significantly lower in LGG as compared with HGG [12]. The usual strategy is to perform a staged volume surgery (with $>=1$ IoMRI), while leaving in place a strategic tumor remnant, to avoid problems related to brain shift and further update neuronavigation [21] with IoMRI.

\section{Supramaximal resection and transient deficit}

Some authors advocate performing a supramaximal resection despite the likelihood of a neurological deficit that hopefully will prove transient, because tissue plasticity and reorganization can further allow subsequent recovery [12]. In some of the studies, this was translated into a survival benefit [12]. However, the molecular biology of the tumors should be more taken into account in such type of studies

\section{Learning curve}

Some of the authors stressed that there was a learning curve in applying these technologies [12]. This is considered related to the fact that surgeons often perform a less aggressive approach to decrease the rate of postoperative neurological deficits, which might result in a suboptimal tumor resection.

Lau et al. [19] further suggested that there is a learning curve associated with the ability to accurately assess intraoperative EOR during glioma surgery, and it may take more than a decade to become truly proficient. Moreover, the authors suggested that understanding the factors associated with the ability to accurately assess EOR will provide safer surgeries while maximizing tumor resection. 


\section{Pitfalls and other adjuvant complementary approaches}

Awake surgery with IoMRI takes longer. Thus, patients must be cooperative and motivated to participate with awake language mapping. Further refinement of the awake technique could be the patient's sedation with Propofol. This has been reported by several centers $[17,35]$ reporting no adverse effects on the cortical stimulation after discontinuation of Propofol. Intraoperative fluorescence-guided resection has been shown to enhance the EOR [52]. One might consider that longer procedures might add to the risk of infection, deep venous thrombosis, and pulmonary embolism [56]. However, the complication rate did not increase [14].

A major aspect is the higher load of surgical information, which is demanding for the surgeons in terms of integration.

\section{Sedation}

Some of the authors [56] reported craniotomy being performed with local anesthesia and intravenous sedation; moreover, intravenous sedation was withdrawn after performing the craniotomy but before opening the dura mater. Other centers considered moderate intravenous sedation (Dexmedetomidine) and generous local anesthesia (bupivacaine) before patient positioning. Lu et al. [24] proposed moderate sedation with boluses of intravenous Propofol, while Tuominen et al. [54] used fentanyl and propofol (and further suspended sedation during cortical stimulation). In the series of Ghinda et al. [12], boluses of porpofol were used, followed by continuous administration of a low dose of remifentanil (0.01 microgrammes $/ \mathrm{Kg} / \mathrm{min}$ ) or Dexmedetomidine (microgrammes/Kg/hour) during mapping.

\section{Overall perspective}

The combine setting of IoMRI and awake microsurgical resection is particularly useful for patients with tumors localized in functional areas. The complete postoperative resection rates might seem lower as classically reported for non-functional locations and the use of IoMRI. One useful strategy is to initially start resection after identifying the eloquent areas by cortical stimulation to optimize resection close to the area. IoMRI would become then useful to evaluate what one has left as residual tumor distant from such areas, to reassess neuronavigation data and optimize resection of this remnant.

\section{Comparative studies}

A first comparative study was performed by Tuominen et al. [54], who compared patients having surgery with IoMRI and awake craniotomy to a group operated under general anesthesia and without cortical stimulation, while keeping the IoMRI setting. The authors concluded that awake craniotomy with bipolar cortical stimulation may help to reduce the risk of postoperative impairment following resection of tumors located in or near speech and motor areas.

A second comparative study by Mehdorn et al. [28] evaluated patients treated with two different approaches: awake craniotomy without (first period) and with (second period) intraoperative MRI. The authors suggested that there was a slight preponderance in redo surgeries for tumor remnant in the first period (11.2\%) as compared with the second (7.4\%). Moreover, the intervals between surgeries in both groups depended mainly on the histological grade. An interesting aspect was that patients with low-grade gliomas in the second series did not experience recurrences as frequently as those in the first series.

\section{Major limitation in the current studies}

One of the major limitations, which should be addressed by further studies, is to correctly report the increment of complete resections from first to last IoMRI. This would better enhance the utility of such an approach and provide the reader a correct information.

A second limitation is related to the awake examination after IoMRI. Moreover, further studies should report the exact number of IoMRI assessments, but also whether or not the patients have been putted into sleep or not during these single/multiple examinations.

\section{Conclusion}

Awake craniotomy with language mapping can be combined successfully with IoMRI to maximize resection of brain tumors in selected patients and preserving neurological function. The technical obstacles to doing so are not severe and can be managed by experienced neurosurgery and anesthesiology teams. The benefits of bringing these technologies to bear on patients with brain tumors in or near language areas are obvious. The lack of equipoise on this topic by experienced practitioners will make it difficult to do a prospective, randomized, clinical trial.

Author contribution Study supervision: Tuleasca, Schulder, Reyns; drafting first version of the article: Tuleasca; revised first draft: all authors; revised final version: all authors; statistical analysis: Tuleasca.

Funding Open Access funding provided by Université de Lausanne. Constantin Tuleasca gratefully acknowledges receipt of a 'Young Researcher in Clinical Research Grant' ("Jeune Chercheur en Recherche Clinique") from the University of Lausanne (UNIL), Faculty of Biology and Medicine (FBM) and the Lausanne University Hospital (CHUV). 
Availability of data and material Data is presented in tables and figures, as it is a systematic review.

Code availability N/A

\section{Declarations}

Ethics approval N/A

Consent to participate N/A

Consent for publication N/A

Conflict of interest The authors declare no competing interests.

Open Access This article is licensed under a Creative Commons Attribution 4.0 International License, which permits use, sharing, adaptation, distribution and reproduction in any medium or format, as long as you give appropriate credit to the original author(s) and the source, provide a link to the Creative Commons licence, and indicate if changes were made. The images or other third party material in this article are included in the article's Creative Commons licence, unless indicated otherwise in a credit line to the material. If material is not included in the article's Creative Commons licence and your intended use is not permitted by statutory regulation or exceeds the permitted use, you will need to obtain permission directly from the copyright holder. To view a copy of this licence, visit http://creativecommons.org/licenses/by/4.0/.

\section{References}

1. Berger MS, Deliganis AV, Dobbins J, Keles GE (1994) The effect of extent of resection on recurrence in patients with low grade cerebral hemisphere gliomas. Cancer 74:1784-1791. https://doi. org/10.1002/1097-0142(19940915)74:6<1784::aidcncr2820740622>3.0.co;2-d

2. Berger MS, Kincaid J, Ojemann GA, Lettich E (1989) Brain mapping techniques to maximize resection, safety, and seizure control in children with brain tumors. Neurosurgery 25:786-792. https:// doi.org/10.1097/00006123-198911000-00015

3. Berger MS, Rostomily RC (1997) Low grade gliomas: functional mapping resection strategies, extent of resection, and outcome. $\mathrm{J}$ Neuro-Oncol 34:85-101. https://doi.org/10.1023/a: 1005715405413

4. Chowdhury T, Zeiler FA, Singh GP, Hailu A, Loewen H, Schaller B, Cappellani RB, West M (2018) The role of intraoperative MRI in awake neurosurgical procedures: a systematic review. Front Oncol 8:434. https://doi.org/10.3389/fonc.2018.00434

5. Coburger J, Merkel A, Scherer M, Schwartz F, Gessler F, Roder C, Pala A, Konig R, Bullinger L, Nagel G, Jungk C, Bisdas S, Nabavi A, Ganslandt O, Seifert V, Tatagiba M, Senft C, Mehdorn M, Unterberg AW, Rossler K, Wirtz CR (2016) Low-grade glioma surgery in intraoperative magnetic resonance imaging: results of a multicenter retrospective assessment of the German Study Group for intraoperative magnetic resonance imaging. Neurosurgery 78 : 775-786. https://doi.org/10.1227/NEU.0000000000001081

6. Comeau RM, Sadikot AF, Fenster A, Peters TM (2000) Intraoperative ultrasound for guidance and tissue shift correction in image-guided neurosurgery. Med Phys 27:787-800. https://doi. org $/ 10.1118 / 1.598942$

7. De Witt Hamer PC, Robles SG, Zwinderman AH, Duffau H, Berger MS (2012) Impact of intraoperative stimulation brain mapping on glioma surgery outcome: a meta-analysis. J Clin Oncol 30:2559-2565. https://doi.org/10.1200/JCO.2011.38.4818

8. Duffau H (2005) Intraoperative cortico-subcortical stimulations in surgery of low-grade gliomas. Expert Rev Neurother 5:473-485. https://doi.org/10.1586/14737175.5.4.473

9. Duffau H, Capelle L, Sichez J, Faillot T, Abdennour L, Law Koune JD, Dadoun S, Bitar A, Arthuis F, Van Effenterre R, Fohanno D (1999) Intra-operative direct electrical stimulations of the central nervous system: the Salpetriere experience with 60 patients. Acta Neurochir 141:1157-1167. https://doi.org/10.1007/ s007010050413

10. Duffau H, Lopes M, Arthuis F, Bitar A, Sichez JP, Van Effenterre R, Capelle L (2005) Contribution of intraoperative electrical stimulations in surgery of low grade gliomas: a comparative study between two series without (1985-96) and with (1996-2003) functional mapping in the same institution. J Neurol Neurosurg Psychiatry 76:845-851. https://doi.org/10.1136/jnnp.2004.048520

11. Gasser T, Szelenyi A, Senft C, Muragaki Y, Sandalcioglu IE, Sure U, Nimsky C, Seifert V (2011) Intraoperative MRI and functional mapping. Acta Neurochir Suppl 109:61-65. https://doi.org/10. 1007/978-3-211-99651-5_10

12. Ghinda D, Zhang N, Lu J, Yao CJ, Yuan S, Wu JS (2016) Contribution of combined intraoperative electrophysiological investigation with 3-T intraoperative MRI for awake cerebral glioma surgery: comprehensive review of the clinical implications and radiological outcomes. Neurosurg Focus 40:E14. https://doi.org/10. 3171/2015.12.FOCUS15572

13. Giussani C, Roux FE, Ojemann J, Sganzerla EP, Pirillo D, Papagno C (2010) Is preoperative functional magnetic resonance imaging reliable for language areas mapping in brain tumor surgery? Review of language functional magnetic resonance imaging and direct cortical stimulation correlation studies. Neurosurgery 66: 113-120. https://doi.org/10.1227/01.NEU.0000360392.15450.C9

14. Hall WA, Liu H, Martin AJ, Pozza CH, Maxwell RE, Truwit CL (2000) Safety, efficacy, and functionality of high-field strength interventional magnetic resonance imaging for neurosurgery. Neurosurgery 46:632-641; discussion 641-632. https://doi.org/10. 1097/00006123-200003000-00022

15. Hatiboglu MA, Weinberg JS, Suki D, Rao G, Prabhu SS, Shah K, Jackson E, Sawaya R (2009) Impact of intraoperative high-field magnetic resonance imaging guidance on glioma surgery: a prospective volumetric analysis. Neurosurgery 64:1073-1081; discussion 1081. https://doi.org/10.1227/01.NEU.0000345647.58219.07

16. Hirschberg H, Samset E, Hol PK, Tillung T, Lote K (2005) Impact of intraoperative MRI on the surgical results for high-grade gliomas. Minim Invasive Neurosurg 48:77-84. https://doi.org/10.1055/ s-2004-830225

17. Huncke K, Van de Wiele B, Fried I, Rubinstein EH (1998) The asleep-awake-asleep anesthetic technique for intraoperative language mapping. Neurosurgery 42:1312-1316; discussion 13161317. https://doi.org/10.1097/00006123-199806000-00069

18. Krivosheya D, Rao G, Tummala S, Kumar V, Suki D, Bastos DCA, Prabhu SS (2019) Impact of multi-modality monitoring using direct electrical stimulation to determine corticospinal tract shift and integrity in tumors using the intraoperative MRI. J Neurol Surg A Cent Eur Neurosurg. https://doi.org/10.1055/s-0039-1698383

19. Lau D, Hervey-Jumper SL, Han SJ, Berger MS (2018) Intraoperative perception and estimates on extent of resection during awake glioma surgery: overcoming the learning curve. $\mathrm{J}$ Neurosurg 128:1410-1418. https://doi.org/10.3171/2017.1. JNS161811

20. Laws ER, Parney IF, Huang W, Anderson F, Morris AM, Asher A, Lillehei KO, Bernstein M, Brem H, Sloan A, Berger MS, Chang S, Glioma Outcomes I (2003) Survival following surgery and prognostic factors for recently diagnosed malignant glioma: data from 
the Glioma Outcomes Project. J Neurosurg 99:467-473. https://doi. org/10.3171/jns.2003.99.3.0467

21. Leroy HA, Delmaire C, Le Rhun E, Drumez E, Lejeune JP, Reyns N (2019) High-field intraoperative MRI and glioma surgery: results after the first 100 consecutive patients. Acta Neurochir 161:14671474. https://doi.org/10.1007/s00701-019-03920-6

22. Leuthardt EC, Lim CC, Shah MN, Evans JA, Rich KM, Dacey RG, Tempelhoff R, Chicoine MR (2011) Use of movable high-fieldstrength intraoperative magnetic resonance imaging with awake craniotomies for resection of gliomas: preliminary experience. Neurosurgery 69:194-205; discussion 205-196. https://doi.org/10. 1227/NEU.0b013e31821d0e4c

23. Liang D, Schulder M (2012) The role of intraoperative magnetic resonance imaging in glioma surgery. Surg Neurol Int 3:S320 S327. https://doi.org/10.4103/2152-7806.103029

24. Lu J, Wu J, Yao C, Zhuang D, Qiu T, Hu X, Zhang J, Gong X, Liang W, Mao Y, Zhou L (2013) Awake language mapping and 3Tesla intraoperative MRI-guided volumetric resection for gliomas in language areas. J Clin Neurosci 20:1280-1287. https://doi.org/ 10.1016/j.jocn.2012.10.042

25. Lu JF, Zhang H, Wu JS, Yao CJ, Zhuang DX, Qiu TM, Jia WB, Mao Y, Zhou LF (2012) "Awake" intraoperative functional MRI (ai-fMRI) for mapping the eloquent cortex: Is it possible in awake craniotomy? NeuroImage Clin 2:132-142. https://doi.org/10.1016/ j.nicl.2012.12.002

26. Maldaun MV, Khawja SN, Levine NB, Rao G, Lang FF, Weinberg JS, Tummala S, Cowles CE, Ferson D, Nguyen AT, Sawaya R, Suki D, Prabhu SS (2014) Awake craniotomy for gliomas in a high-field intraoperative magnetic resonance imaging suite: analysis of 42 cases. J Neurosurg 121:810-817. https://doi.org/10.3171/ 2014.6.JNS132285

27. Martin C, Alexander E 3rd, Wong T, Schwartz R, Jolesz F, Black PM (1998) Surgical treatment of low-grade gliomas in the intraoperative magnetic resonance imager. Neurosurg Focus 4:E8. https:// doi.org/10.3171/foc.1998.4.4.11

28. Mehdorn HM, Schwartz F, Becker J (2017) Awake craniotomy for tumor resection: further optimizing therapy of brain tumors. Acta Neurochir Suppl 124:309-313. https://doi.org/10.1007/978-3-31939546-3 45

29. Moher D, Liberati A, Tetzlaff J, Altman DG, Group P (2009) Reprint-preferred reporting items for systematic reviews and meta-analyses: the PRISMA statement. Phys Ther 89:873-880

30. Motomura K, Natsume A, Iijima K, Kuramitsu S, Fujii M, Yamamoto T, Maesawa S, Sugiura J, Wakabayashi T (2017) Surgical benefits of combined awake craniotomy and intraoperative magnetic resonance imaging for gliomas associated with eloquent areas. J Neurosurg 127:790-797. https://doi.org/10.3171/ 2016.9.JNS16152

31. Nabavi A, Goebel S, Doerner L, Warneke N, Ulmer S, Mehdorn M (2009) Awake craniotomy and intraoperative magnetic resonance imaging: patient selection, preparation, and technique. Top Magn Reson Imaging 19:191-196. https://doi.org/10.1097/RMR. 0b013e3181963b46

32. Nimsky C, Ganslandt O, Buchfelder M, Fahlbusch R (2006) Intraoperative visualization for resection of gliomas: the role of functional neuronavigation and intraoperative 1.5 T MRI. Neurol Res 28:482-487. https://doi.org/10.1179/016164106X115125

33. Oh DS, Black PM (2005) A low-field intraoperative MRI system for glioma surgery: is it worthwhile? Neurosurg Clin N Am 16: 135-141. https://doi.org/10.1016/j.nec.2004.07.010

34. Ojemann G, Ojemann J, Lettich E, Berger M (1989) Cortical language localization in left, dominant hemisphere. An electrical stimulation mapping investigation in 117 patients. J Neurosurg 71:316326. https://doi.org/10.3171/jns.1989.71.3.0316

35. Olsen KS (2008) The asleep-awake technique using propofolremifentanil anaesthesia for awake craniotomy for cerebral tumours. Eur J Anaesthesiol 25:662-669. https://doi.org/10.1017/ S0265021508003633

36. Parney IF, Goerss SJ, McGee K, Huston J 3rd, Perkins WJ, Meyer FB (2010) Awake craniotomy, electrophysiologic mapping, and tumor resection with high-field intraoperative MRI. World Neurosurg 73:547-551. https://doi.org/10.1016/j.wneu.2010.02. 003

37. Penfield W, Boldrey E (1937) Somatic motor and sensory representation in the cerebral cortex of man as studied by electrical stimulation. Brain 60:389-443

38. Peruzzi P, Puente E, Bergese S, Chiocca EA (2011) Intraoperative MRI (ioMRI) in the setting of awake craniotomies for supratentorial glioma resection. Acta Neurochir Suppl 109:43-48. https://doi.org/ 10.1007/978-3-211-99651-5 7

39. Petrovich Brennan NM, Whalen S, de Morales BD, O'Shea JP, Norton IH, Golby AJ (2007) Object naming is a more sensitive measure of speech localization than number counting: converging evidence from direct cortical stimulation and fMRI. Neuroimage 37(Suppl 1):S100-S108. https://doi.org/10.1016/j.neuroimage. 2007.04.052

40. Piccioni F, Fanzio M (2008) Management of anesthesia in awake craniotomy. Minerva Anestesiol 74:393-408

41. Prabhu SS, Gasco J, Tummala S, Weinberg JS, Rao G (2011) Intraoperative magnetic resonance imaging-guided tractography with integrated monopolar subcortical functional mapping for resection of brain tumors. Clinical article. J Neurosurg 114:719-726. https://doi.org/10.3171/2010.9.JNS10481

42. Raabe A, Beck J, Schucht P, Seidel K (2014) Continuous dynamic mapping of the corticospinal tract during surgery of motor eloquent brain tumors: evaluation of a new method. J Neurosurg 120:10151024. https://doi.org/10.3171/2014.1.JNS13909

43. Reyns N, Leroy HA, Delmaire C, Derre B, Le-Rhun E, Lejeune JP (2017) Intraoperative MRI for the management of brain lesions adjacent to eloquent areas. Neuro-Chirurgie 63:181-188. https:// doi.org/10.1016/j.neuchi.2016.12.006

44. Sanai N, Berger MS (2008) Glioma extent of resection and its impact on patient outcome. Neurosurgery 62:753-764; discussion 264-756. https://doi.org/10.1227/01.neu.0000318159.21731.cf

45. Sanai N, Mirzadeh Z, Berger MS (2008) Functional outcome after language mapping for glioma resection. N Engl J Med 358:18-27. https://doi.org/10.1056/NEJMoa067819

46. Sartorius CJ, Berger MS (1998) Rapid termination of intraoperative stimulation-evoked seizures with application of cold Ringer's lactate to the cortex. Technical note. J Neurosurg 88:349-351. https:// doi.org/10.3171/jns.1998.88.2.0349

47. Sartorius CJ, Wright G (1997) Intraoperative brain mapping in a community setting-technical considerations. Surg Neurol 47:380 388. https://doi.org/10.1016/s0090-3019(96)00340-0

48. Schulder M, Carmel PW (2003) Intraoperative magnetic resonance imaging: impact on brain tumor surgery. Cancer Control 10:115124. https://doi.org/10.1177/107327480301000203

49. Senft C, Bink A, Franz K, Vatter H, Gasser T, Seifert V (2011) Intraoperative MRI guidance and extent of resection in glioma surgery: a randomised, controlled trial. Lancet Oncol 12:997-1003. https://doi.org/10.1016/S1470-2045(11)70196-6

50. Shiban E, Krieg SM, Haller B, Buchmann N, Obermueller T, Boeckh-Behrens T, Wostrack M, Meyer B, Ringel F (2015) Intraoperative subcortical motor evoked potential stimulation: how close is the corticospinal tract? J Neurosurg 123:711-720. https://doi.org/10.3171/2014.10.JNS141289

51. Spena G, Nava A, Cassini F, Pepoli A, Bruno M, D'Agata F, Cauda F, Sacco K, Duca S, Barletta L, Versari P (2010) Preoperative and intraoperative brain mapping for the resection of eloquent-area tumors. A prospective analysis of methodology, correlation, and usefulness based on clinical outcomes. Acta Neurochir 152:18351846. https://doi.org/10.1007/s00701-010-0764-9 
52. Stummer W, Novotny A, Stepp H, Goetz C, Bise K, Reulen HJ (2000) Fluorescence-guided resection of glioblastoma multiforme by using 5 -aminolevulinic acid-induced porphyrins: a prospective study in 52 consecutive patients. J Neurosurg 93:1003-1013. https://doi.org/10.3171/jns.2000.93.6.1003

53. Tonn JC (2007) Awake craniotomy for monitoring of language function: benefits and limits. Acta Neurochir 149:1197-1198. https://doi.org/10.1007/s00701-007-1368-x

54. Tuominen J, Yrjana S, Ukkonen A, Koivukangas J (2013) Awake craniotomy may further improve neurological outcome of intraoperative MRI-guided brain tumor surgery. Acta Neurochir 155: 1805-1812. https://doi.org/10.1007/s00701-013-1837-3

55. Walker JA, Quinones-Hinojosa A, Berger MS (2004) Intraoperative speech mapping in 17 bilingual patients undergoing resection of a mass lesion. Neurosurgery 54:113-117; discussion 118. https://doi.org/10.1227/01.neu.0000097270.95721.3b

56. Weingarten DM, Asthagiri AR, Butman JA, Sato S, Wiggs EA, Damaska B, Heiss JD (2009) Cortical mapping and frameless stereotactic navigation in the high-field intraoperative magnetic resonance imaging suite. J Neurosurg 111:1185-1190. https://doi.org/ 10.3171/2009.5.JNS09164

57. Whitaker HA, Ojemann GA (1977) Graded localisation of naming from electrical stimulation mapping of left cerebral cortex. Nature 270:50-51. https://doi.org/10.1038/270050a0
58. White T, Zavarella S, Jarchin L, Nardi D, Schaffer S, Schulder M (2018) Combined brain mapping and compact intraoperative MRI for brain tumor resection. Stereotact Funct Neurosurg 96:172-181. https://doi.org/10.1159/000488991

59. Whiting BB, Lee BS, Mahadev V, Borghei-Razavi H, Ahuja S, Jia X, Mohammadi AM, Barnett GH, Angelov L, Rajan S, Avitsian R, Vogelbaum MA (2019) Combined use of minimal access craniotomy, intraoperative magnetic resonance imaging, and awake functional mapping for the resection of gliomas in 61 patients. $J$ Neurosurg 1-9. https://doi.org/10.3171/2018.9.JNS181802

60. Zemmoura I, Fournier E, El-Hage W, Jolly V, Destrieux C, Velut S (2016) Hypnosis for awake surgery of low-grade gliomas: description of the method and psychological assessment. Neurosurgery 78: 53-61. https://doi.org/10.1227/NEU.0000000000000993

61. Zhuang DX, Wu JS, Yao CJ, Qiu TM, Lu JF, Zhu FP, Xu G, Zhu W, Zhou LF (2016) Intraoperative multi-information-guided resection of dominant-sided insular gliomas in a 3-T intraoperative magnetic resonance imaging integrated neurosurgical suite. World Neurosurg 89:84-92. https://doi.org/10.1016/j.wneu.2016.01.067

Publisher's note Springer Nature remains neutral with regard to jurisdictional claims in published maps and institutional affiliations. 